\title{
Measurement of regional cerebral blood volume by computerized axial tomography
}

\author{
G. LADURNER, E. ZILKHA, LINNETTE D. ILIFF, G. H. DU BOULAY, \\ AND JOHN MARSHALL ${ }^{1}$ \\ From the Institute of Neurology and the National Hospital for Nervous Diseases, \\ Queen Square, London
}

SYNOPSIS Computerized tomography has been used for the estimation of regional cerebral blood volume in a group of 18 patients. Sodium iothalamate was injected intravenously $(1.75 \mathrm{ml} / \mathrm{kg})$ to increase the absorption of $x$-rays in the cerebral circulation. A mean value of $5.7 \mathrm{ml} / 100 \mathrm{~g}$ was found for the cortex and 5.1 for the thalamus.

Computerized transverse axial scanning (EMIScanning) is a technique by which a two dimensional picture of the intracranial tissues can be constructed from their varying absorptions of an $x$-ray beam. Details of the system can be found in the paper by the inventor G. N. Hounsfield (1973). The absorption coefficient of a tissue can be calculated from the difference between the intensity of the original $x$-ray beam at source and the intensity of the emergent rays from the head by the following formula:

Absorption $=\log \frac{\text { intensity of } x \text {-ray source }}{\text { intensity of } x \text {-rays at detector }}$

(Hounsfield, 1973).

During a scan 43200 simultaneous equations are computer calculated to estimate the absorption values in a 'slice' of brain tissue consisting of 25600 blocks (cells) of tissue each with dimensions $1.5 \times 1.5 \times 13 \mathrm{~mm}$. The numerical print out of the absorption values in a 'slice' appears as a matrix of $160 \times 160$ cells.

Differences as low as $0.5 \%$ in the EMI number between cells can be detected and as the difference between most pathological tissue and normal brain exceeds this they can be accurately demonstrated. However, there are some patho-

1 Address for correspondence: Professor John Marshall, University Department of Clinical Neurology, The National Hospital, Queen Square, London WC1N 3BG.

(Accepted 29 August 1975.) logical tissues-such as some tumours and infarcts at a certain stage of evolution-the EMI $\overrightarrow{0}$ numbers of which are very close to that of normal brain, so that visualization by EMI scanning is difficult. The intravenous injection of sodium iothalamate among other contrast media increases the EMI number of tumour tissue and so permits its visualization (Ambrose, 1973) Ambrose (1974) has suggested that damage to the blood brain barrier allows sodium iothalamate to enter the interstitial tissue, so increasing the EMI number. This has also been seen to occur in cases of cerebral infarction (Ambrose, 1975, personal communication). Another explanation is that vascular tissue will show increased absorption because of the high content of the sodium iothalamate in the blood (New et al., 1974). Both explanations are possible depending upon the type of tumour tissue and the time after injection (Bergvall, 1975). Clearly, the increased EMI number of tissue after administration of sodium iothalamate requires further investigation, which was the reason for the present study.

Evidence of the time course for equilibrium of contrast media between the vascular and extravascular compartments is conflicting. Denneberg (1965) showed in studies on human subjects that it required 80-120 minutes. Others, including Cattell et al. (1967) and Cattell (1970), showed that equilibrium was reached within the first 10 152 
minutes after the introduction of contrast medium into the circulation.

Ter-Pogossian and his colleagues (1972) showed that sodium iothalamate does not traverse the blood brain barrier. They used two methods when measuring regional cerebral blood volume (rCBV); the first employed ${ }^{51} \mathrm{Cr}$ labelled red blood cells and the second an $x$-ray fluoroscopic method using sodium iothalamate. Results of similar magnitude were obtained from both methods, indicating that the contrast medium had remained in the vascular compartment. Had some of it gone into the extravascular compartment, regional CBV would have been substantially overestimated by the sodium iothalamate method.

More recently, it has been shown that, after the injection of sodium iothalamate, the absorption coefficient can be increased in normal tissue as well as in vascular tumours (New et al., 1974). In these circumstances, it is theoretically possible to subtract the pre-injection from the postinjection EMI number to determine the change in tissue absorption due to the increase in density of the blood as a result of the presence of contrast medium. If the concentration of sodium iothalamate in the blood is known at the time of a scan then this, together with the increase in tissue absorption after injection of contrast medium, can be used to estimate cerebral blood volume. Our objectives were first to establish whether a significant change in the EMI number was evident after the injection of sodium iothalamate and, if so, to use this to estimate rCBV.

\section{METHODS}

Eighteen patients were studied (five men and 13 women), the clinical details of whom are shown in Table 1 .

All the EMI scans were made at $120 \mathrm{keV}$ with the patient movement control (PMC) programme in operation. Two cuts (referred to as 2A and 2B) 43 and $56 \mathrm{~mm}$ respectively above the orbitomeatal line were made and repeated after injection of 90 to $120 \mathrm{ml}$ sodium iothalamate (Conray 420) over one to two minutes into an arm vein while the patient remained in the identical position. The dose was varied because some patients felt nauseated and were therefore given less. The mean dose was $1.75 \mathrm{ml} / \mathrm{kg}$ body weight. Heparinized blood samples were taken from a contralateral arm vein at intervals of one, three, and five minutes after the start of the scan at the end of the sodium iothalamate injection to estimate the blood concentration. The values were averaged to give a mean over the $6 \frac{1}{2}$ minute period of the scan.

The sodium iothalamate concentration in the blood was measured in two ways. A spectrophotometric method comparing the plasma from the blood samples with a known solution of sodium iothalamate (Purkiss et al., 1968) was employed in 14 patients and expressed in $\mathrm{mg} / 100 \mathrm{ml}$ of plasma. The second method used the EMI-Scanner to measure the absorption values in a phantom containing samples of whole blood and of plasma taken before and after injection of sodium iothalamate, comparing them with samples of known concentrations. This method was used in five patients, both methods being used in one case. In five patients the haematocrit was estimated to measure how much haemodilution had occurred as a result of the sodium iothalamate injection.

It was impossible in every case to obtain normal data from both hemispheres because of the presence of pathological tissue, so that data from one hemisphere only from each patient were used. The digital print-out of the EMI-Scan was divided into frontal, temporal, and occipital regions of the cortex and from these three areas a field of 108 square mm (48 cells) was selected for comparison of mean EMI numbers before and after injection of sodium iothalamate. Areas containing obvious sulci or other anatomical structures were avoided, as were artefacts due to movement.

Samples were also taken from an area of homogeneous grey matter-namely, the thalamus. In most cases the area of the thalamus which it was possible to sample was not as large as that of the cortex. Accordingly, seven cases in which normal areas contained not less than 32 cells from the thalami on both sides were selected.

PHANTOM STUDIES A phantom was constructed from a cylindrical plastic container filled with liquid, inside which a transverse section approximately $5 \mathrm{~cm}$ ( 2 in.) high of a skull was placed; inside this, six sample bottles were fixed. As a substantial amount of blood would be required to prepare six $10 \mathrm{ml}$ samples, $5 \mathrm{ml}$ of distilled water were added in the following combinations:

1. $5 \mathrm{ml}$ blood before injection of sodium iothalamate mixed with $5 \mathrm{ml}$ distilled water

2. $5 \mathrm{ml}$ plasma before injection of iothalamate mixed with $5 \mathrm{ml}$ distilled water

3. $5 \mathrm{ml}$ blood before injection of iothalamate mixed with a $5 \mathrm{ml}$ solution of $0.8 \mathrm{ml}$ iothalamate in $100 \mathrm{ml}$ distilled water 


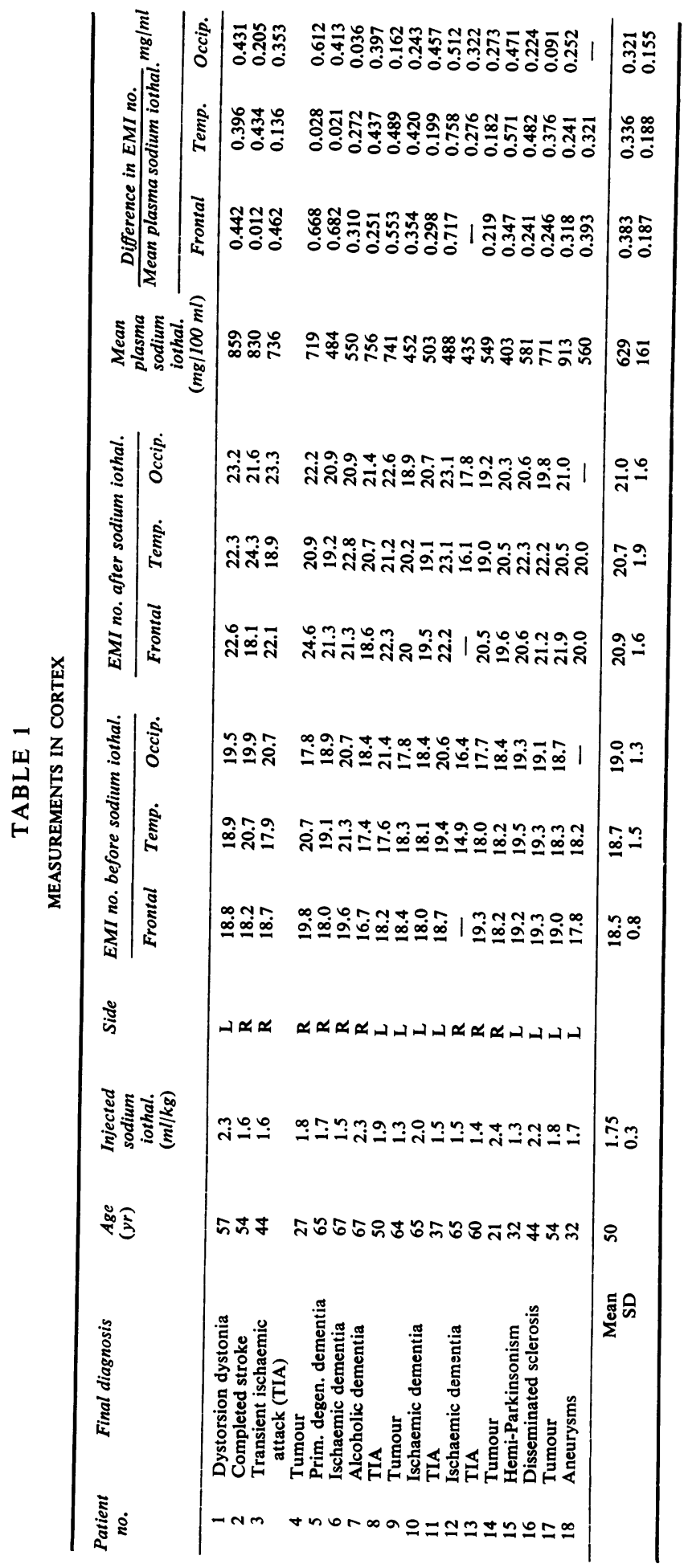


4. $5 \mathrm{ml}$ blood obtained $1 \mathrm{~min}$ after end of injection of iothalamate mixed with $5 \mathrm{ml}$ distilled water

5. $5 \mathrm{ml}$ blood obtained $5 \mathrm{~min}$ after end of injection of iothalamate mixed with $5 \mathrm{ml}$ distilled water

6. $5 \mathrm{ml}$ plasma obtained $5 \mathrm{~min}$ after end of injection of iothalamate mixed with $5 \mathrm{ml}$ distilled water.

The following facts were established by means of the phantom studies:

1. EVIDENCE FOR SODIUM IOTHALAMATE BEING CONFINED TO PLASMA In 14 patients the plasma sodium iothalamate was estimated spectrophotometrically, the assumption being that all the sodium iothalamate is in plasma. When the EMI number for blood alone is subtracted from blood plus sodium iothalamate (sample 5-1) the resulting value was (within experimental error) the same as that of plasma alone subtracted from plasma plus sodium iothalamate $(6-2)$, providing that the haematocrit was taken into account. This indicates that sodium iothalamate is present only in the plasma.

2. PLASMA CONCENTRATION OF SODIUM IOTHALAMATE In five patients plasma sodium iothalamate was measured using the phantom. The EMI number for plasma before injection of sodium iothalamate was subtracted from the EMI number for plasma after the injection of sodium iothalamate (6-2) giving the value due to sodium iothalamate. To calculate the EMI number resulting from a known concentration of sodium iothalamate, the EMI number for a solution (we have used blood but it can be any solution) is subtracted from the EMI number of a known concentration of sodium iothalamate in that solution (3-1). This value we will call the "calibration factor'. If only plasma were present in the patient's head, then the EMI number difference after the injection of sodium iothalamate would be identical with the EMI number difference in plasma after the injection of sodium iothalamate. But the skull contains plasma and brain, therefore the EMI number difference is smaller in proportion to the ratio of plasma volume to brain. Therefore, the regional plasma volume can be calculated from the following expression:

$\%$ Regional plasma volume $=$

difference in EMI number brain
change in plasma EMI number due to
sodium iothalamate

where the denominator is obtained from the phantom measurements.

3. REGIONAL CEREBRAL BLOOD VOLUME CALCULATION Knowing the haematocrit, the regional blood volume can be calculated from the regional plasma volume.

\section{RESULTS}

SODIUM IOTHALAMATE MEASUREMENTS The mean plasma sodium iothalamate level in Table 1 was obtained from the three samples taken during the $6 \frac{1}{2}$ minute period of scanning. This was necessary because the concentration fell during this period by an average of $14 \%$ (range 0-37). There was no significant correlation between the dose of sodium iothalamate injected and the plasma level, possibly because of different degrees of hydration and rate of injection (Cattell, 1970). The increase in EMI number in each of the three cortical areas after injection of sodium iothalamate divided by its concentration $(\mathrm{mg} / \mathrm{ml})$ in the plasma is shown in the last three columns of Table 1 .

Plasma levels measured a minute after injection of sodium iothalamate suggest that over two-thirds of the iothalamate has left the vascular compartment in this time by crossing into the extracellular space of the body and kidneys though not in the brain, some excretion having taken place by two minutes. This rapid exit from the vascular compartment seems to be in agreement with the results obtained by other investigators using sodium diatrizoate (Hypaque) (Cattell et al., 1967; Cattell, 1970).

EMI-SCAN NUMBERS IN CORTEX EMI-Scan numbers obtained from the numerical printouts $(160 \times 160$ matrix $)$ from the frontal, temporal, and occipital areas are shown in Table 1. One area in each of three patients was excluded because of localized artefacts. Mean results for the three cortical areas are similar, being 18.5, 18.4 , and 18.7 in the frontal, temporal, and occipital areas respectively. There was, however, considerable individual variation not only from patient to patient but also in the three areas from any one patient; presumably this was mainly because of the difficulty in ensuring that grey matter only was included in the samples. After the injection of sodium iothalamate (mean dose $1.75 \mathrm{ml} / \mathrm{kg}$ ) the EMI-Scan numbers are significantly higher than before by a mean of 2.2 $(P<0.001)$. The enhanced values are very similar in the three areas.

EMI-SCAN NUMBERS IN THALAMUS Table 2 shows the mean increase in EMI-Scan numbers in the 
TABLE 2

MEASUREMENTS IN THALAMUS

\begin{tabular}{|c|c|c|c|c|c|c|}
\hline \multirow[t]{2}{*}{$\begin{array}{l}\text { Patient } \\
\text { no. }\end{array}$} & \multicolumn{2}{|c|}{$\begin{array}{c}\text { EMI no. } \\
\text { before sodium iothalamate }\end{array}$} & \multicolumn{2}{|c|}{$\begin{array}{l}\text { EMI no. } \\
\text { after sodium iothalamate }\end{array}$} & \multicolumn{2}{|c|}{$\frac{\text { Difference in EMI no. }}{\text { Mean plasma sodium iothalamate }} \mathrm{mg} / \mathrm{ml}$} \\
\hline & $R$ & $L$ & $R$ & $L$ & $R$ & $L$ \\
\hline $\begin{array}{r}1 \\
2 \\
5 \\
8 \\
11 \\
12 \\
15\end{array}$ & $\begin{array}{l}16.5 \\
16.9 \\
18.2 \\
18.5 \\
17.0 \\
17.7 \\
19.3\end{array}$ & $\begin{array}{l}18.6 \\
18.2 \\
17.9 \\
17.9 \\
17.3 \\
17.2 \\
17.0\end{array}$ & $\begin{array}{l}18.6 \\
19.4 \\
19.6 \\
20.6 \\
18.3 \\
19.2 \\
20.3\end{array}$ & $\begin{array}{l}20.6 \\
21.3 \\
20.0 \\
21.3 \\
19.3 \\
18.1 \\
19.3\end{array}$ & $\begin{array}{l}0.244 \\
0.301 \\
0.289 \\
0.283 \\
0.266 \\
0.276 \\
0.172\end{array}$ & $\begin{array}{l}0.233 \\
0.373 \\
0.434 \\
0.459 \\
0.410 \\
0.207 \\
0.275\end{array}$ \\
\hline & $\begin{array}{r}17.7 \\
1.0\end{array}$ & $\begin{array}{r}17.7 \\
0.6\end{array}$ & $\begin{array}{r}19.4 \\
0.8\end{array}$ & $\begin{array}{r}20.0 \\
1.0\end{array}$ & $\begin{array}{l}0.262 \\
0.043\end{array}$ & $\begin{array}{l}0.342 \\
0.102\end{array}$ \\
\hline
\end{tabular}

TABLE 3

REGIONAL CEREBRAL BLOOD VOLUME IN CORTEX AND tHALAMUS ( $\mathrm{ml} / 100 \mathrm{~g}$ )

\begin{tabular}{|c|c|c|c|c|c|c|c|}
\hline \multirow{2}{*}{$\begin{array}{c}\text { Patient } \\
\text { no. }\end{array}$} & \multicolumn{3}{|c|}{ Cortical rCBV } & \multirow[t]{2}{*}{ Mean } & \multicolumn{2}{|c|}{ Thalamic $r C B V$} & \multirow[t]{2}{*}{ Mean } \\
\hline & Frontal & Temporal & Occipital & & Right & Left & \\
\hline 1 & 6.9 & 6.2 & 6.7 & 6.6 & 3.8 & 3.6 & 3.7 \\
\hline 2 & 0 & 7.4 & 3.5 & 5.5 & 5.2 & 6.4 & 5.8 \\
\hline 3 & 8.0 & 2.4 & 6.1 & 5.5 & & & \\
\hline 4 & 10.6 & 0.5 & 9.8 & 7.0 & & & \\
\hline 5 & 11.9 & 0.4 & 7.2 & 6.5 & 5.1 & 7.6 & 6.4 \\
\hline 6 & 5.4 & 4.8 & 0.6 & 3.6 & & & \\
\hline 7 & 4.1 & 7.1 & 6.5 & 5.9 & & & \\
\hline 8 & 9.2 & 8.1 & 2.7 & 6.7 & 4.7 & 7.6 & 6.2 \\
\hline 9 & 5.9 & 7.0 & 4.1 & 5.7 & & & \\
\hline 10 & 5.4 & 3.6 & 8.3 & 5.8 & & & \\
\hline 11 & 11.3 & 11.9 & 8.1 & 10.4 & 4.2 & 6.2 & 5.4 \\
\hline 12 & - & 48 & 5.6 & 5.2 & 4.8 & 3.6 & 4.2 \\
\hline 13 & 3.4 & 2.8 & 4.2 & 3.5 & & & \\
\hline 14 & 5.7 & 9.4 & 7.7 & 7.6 & & & \\
\hline 15 & 4.4 & 8.7 & 4.0 & 5.7 & 3.1 & 5.0 & 4.1 \\
\hline 16 & 4.2 & 6.4 & 15 & 4.0 & & & \\
\hline 17 & 5.2 & 4.0 & 4.1 & 4.4 & & & \\
\hline 18 & 6.3 & 5.1 & - & 5.7 & & & \\
\hline \multirow{2}{*}{\multicolumn{2}{|c|}{$\begin{array}{r}\text { Mean } \\
\text { SD }\end{array}$}} & 5.6 & 5.3 & 5.7 & 4.4 & 5.8 & 5.1 \\
\hline & & 3.0 & 2.5 & 1.6 & 0.8 & 1.7 & 1.0 \\
\hline
\end{tabular}

thalami after the injection of sodium iothalamate as 2.0 which is a highly significant change $(P<0.001)$. When the increase divided by the plasma sodium iothalamate level (last column in Table 2) was compared for the right and left thalami, the left was marginally greater $(\mathrm{P}<0.05)$.

The calibration factor of 60.3 (SD 2.5) was obtained for a solution of $1 \mathrm{ml}$ sodium iothalamate $/ 100 \mathrm{ml}$ in the phantom. The plasma volume was calculated by dividing the increase in EMI number by the calibration factor of 60.3. To obtain the blood volume the plasma volume was multiplied by $100 /(100-N)$ where $N$ is the final haematocrit; it is called the 'final haematocrit' because two corrections have to be made for the following reasons. After the injection of sodium iothalamate, there was a mean fall in haematocrit of $16 \%$ in the five patients in whom it was measured. We have corrected for this in the calculation of rCBV. The second factor is that the haematocrit of blood in the cerebral circulation has been reported to be approximately $15 \%$ less than that for the large vessels Larsen and Lassen, 1964; Oldendorf et al., 1965), so this factor also has been applied in the calcula- 
tions of rCBV, the results of which are shown in Table 3.

The mean $\mathrm{rCBV}$ for the frontal, temporal, and occipital areas was $6.3,5.6$, and $5.3 \mathrm{ml} / 100 \mathrm{~g}$ tissue respectively. Individual values showed considerable variation both between patients and between areas in any one patient. This is reflected in the mean and standard deviation, which (column 5 ) was $28 \%$ between patients.

In the thalamus the mean rCBV on the right side was 4.4 and on the left 5.8. The standard deviation was $20 \%$ for the right and left sides taken together (last column), but for the right side it was lower than for the left.

\section{DISCUSSION}

Regional cerebral blood volume is an important index in the evaluation of the cerebral circulation both in the normal and pathological situation but one which it is difficult to measure. Previous methods have included radioactive labelling of plasma or red cells with tissue estimations or external counting (Sklar et al., 1968; Risberg et al., 1969), the use of mean transit times of a non-diffusible indicator combined with cerebral blood flow measurements (Smith et al., 1971), and more recently $x$-ray fluorescent techniques (Grubb et al., 1973).

The last of the methods has the advantages of being non-invasive and of giving results on a regional basis, though the localization is not as precise as the EMI-Scan approach described here. EMI scanning allows the measurements to be made in areas of choice as well as in whole cross-sections of the brain at a variety of anatomical levels. The resolution is of the order of $1.5 \mathrm{~mm}$ so that most pathological tissue can be defined.

One major disadvantage of the method is the small increase in EMI number after the injection of sodium iothalamate (average value 2.2); because of this, a relatively large area has to be sampled to achieve reasonable accuracy. This presents difficulties because the sample may not then be homogeneous as it may include sulci and blood vessels as well as grey and white matter.

A technical difficulty is to keep the patient's head still for the duration of the investigation. Movement may make impossible the accurate superimposition of the two scans in order to subtract the pre- from the post-injection EMI numbers, particularly if the movement is perpendicular to the plane of the scan. In addition, movement may cause artefacts.

This method of measuring CBV, in common with other methods, relies upon the indicator not crossing the blood brain barrier during the time of measurement. Ter-Pogossian et al. (1972) showed this to be so for sodium iothalamate. Since the extravascular compartment in the brain is considered to be less than $1 \%$ of the total volume (Bito et al., 1966; Lassen et al., 1971), its inclusion in rCBV measurements would lead to only a small overestimation. We have noticed less uptake of sodium iothalamate in oedematous areas than in surrounding normal tissue, giving further evidence for sodium iothalamate remaining in the cerebral vascular compartment.

Our mean cortical rCBV of $5.7 \mathrm{ml} / 100 \mathrm{~g}$ (SD 1.6) is significantly higher than the value of $3.2 \mathrm{ml} / 100 \mathrm{~g}$ (SD 0.94) measured by Grubb et al. (1973). This may be because in the present study sampling was limited to the cortex where it is likely that the rCBV will be higher than in areas where there is a mixture of grey and white matter. Also, if the sample happens to include some large vessels the rCBV will be overestimated. On the other hand, the difference between the two studies may be due to the timing of the measurement after the injection of contrast medium. It has already been mentioned that the total blood volume increases by $16 \%$ after the injection of sodium iothalamate. At this time, rCBV may be artificially high. Therefore our estimations, being earlier, would be expected to give higher values.

The relatively large SDs obtained by the present method are mainly due to the method of measurement rather than to differences in rCBV between patients and between cortical areas. After the injection of sodium iothalamate, the mean increase in EMI number was only 2.2. This means that even a small error in the measurement ( 0.5 of an EMI number) will introduce an error of about $25 \%$ in the estimated value for rCBV. Had increase in EMI number been greater, or the sampling area larger, the estimations would undoubtedly be more accurate.

The EMI number difference can be increased 
by injecting a higher dose of sodium iothalamate. An increase in the area sampled requires computer assisted subtraction if tedious calculations are to be avoided; this will be the subject of a future communication.

The present study has shown that measurement of rCBV using the EMI-Scanner is possible. More work is required before its level of accuracy is adequate for clinical use.

Invaluable help was provided by the radiographers and Miss B. Cummack in spectrophotometric estimations of plasma iothalamate. We thank Miss B. Laatz for her assistance in the preparation of the manuscript.

\section{REFERENCES}

Ambrose, J. (1973). Computerized transverse axial scanning (tomography): Part 2. Clinical application. British Journal of Radiology, 46, 1023-1047.

Ambrose, J. (1974). Computerized $x$-ray scanning of the brain. Journal of Neurosurgery, 40, 679-695.

Bergvall, U. (1975). Computerized Axial Tomography and Angiography (EMI-scanner). Enhancement of Results by Injections of Contrast Media, Symposium. INSERM: Marseille.

Bito, L. Z., Bradbury, W. B., and Davson, H. (1966). Factors affecting the distribution of iodide and bromide in the central nervous system. Journal of Physiology, 185, 323-354.

Cattell, W. R. (1970). Excretory pathways for contrast media. Investigative Radiology, 5, 473-486.

Cattell, W. R., Kelsey Fry, I., Spencer, A. G., and Purkiss, P. (1967). Excretion urography. 1-Factors determining the excretion of Hypaque. British Journal of Radiology, 40, 561-580.

Denneberg, T. (1965). Clinical studies of kidney function with radioactive sodium diatrizoate (Hypaque). Acta Medica Scandinavica, Suppl. 442.
Grubb, R. I., Phelps, M. E., and Ter-Pogossian, M. M. (1973). Regional cerebral blood volume in humans. Archives of Neurology, 28, 38-44.

Hachinski, V. C., Iliff, Linnette D., Zilkha, E., Du Boulay, G. H., McAllister, V. L., Marshall, John, Ross Russell, R. W., and Symon, Lindsay. (1975). Cerebral blood flow in dementia. Archives of Neurology. (In press.)

Hounsfield, G. N. (1973). Computerized transverse axial scanning (tomography): Part 1. Description of system. British Journal of Radiology, 46, 1016-1022.

Larsen, O. A., and Lassen, N. A. (1964). Cerebral hematocrit in normal man. Journal of Applied Physiology, 19, 571-574.

Lassen, N. A., Trap-Jensen, J., Alexander, S. C., Olesen, J., and Paulsen, O. B. (1971). Blood brain barrier studies in man using the double-indicator method. American Journal of Physiology, 220, 1627-1633.

New, P. F. J., Scott, W. R., Schnur, J. A., Davis, K. R., and Taveras, J. M. (1974). Computerized axial tomography with the EMI scanner. Radiology, 110, 109-123.

Oldendorf, W. H., Kitano, M., Schimizu, S., and Oldendorf, S. Z. (1965). Hematocrit of the human cranial pool. Circulation Research, 17, 532-539.

Purkiss, P., Lane, R. D., Cattell, W. R., Kelsey Fry, I., and Spencer, A. G. (1968). Estimation of sodium diatrizoate by absorption spectrophotometry. Investigative Radiology, 3, 271-274.

Risberg, J., Ancri, D., and Ingvar, D. H. (1969). Correlation between cerebral blood volume and cerebral blood flow in the cat. Experimental Brain Research, 8, 321-326.

Sklar, F. S., Burke, E. F., and Langfitt, T. W. (1968). Cerebral blood volume: values obtained with ${ }^{51} \mathrm{Cr}$-labeled red blood cells and RISA. Journal of Applied Physiology, 24, 79-82.

Smith, A. L., Neufeld, G. R., Ominsky, A. J., and Wollman, H. (1971). Effect of arterial $\mathrm{CO}_{2}$ tension on cerebral blood flow, mean transit time, and vascular volume. Journal of Applied Physiology, 31, 701-707.

Ter-Pogossian, M. M., Phelps, M. E., Grubb, R. L., and Gado, M. (1972). Measure of regional cerebral blood volume in vivo by means of excited fluorescent $\mathrm{X}$-radiation, and factors affecting this parameter. Proceedings of the 5th International Symposium, Roma-Siena 1971, Part 1. European Neurology, 6, 218-223. 